\title{
AUTOMATIC TRACKING SYSTEM FOR SOLAR CELLS
}

\section{Azzam, Attia El-Sbaie, Faculty of Engineering. , Menoufia Univ. ,Shibeen El-Kom, Egypt}

\begin{abstract}
:
The purpose of this paper is designing and study the performance of PV tracking system to get maximum power output. A suggested automatic tracking system to make PV system oriented always facing perpendicular to the sun along a day time, since sunrise tell sunset is presented. This tracking system consists of sensors, comparator circuits to get the direction of motion and to drive stepper motors until get the equilibrium which is facing and perpendicular to the sun. Two tracking subsystems are designed for the proposed automatic closed loop tracking system. These are one for horizontal equilibrium and the other for vertical ones.
\end{abstract}

\section{LIST OF SYMBOLS:}

Lx, Ly Horizontal and Vertical deflection branches for control system.

Ax, Bx Right and Left sensors for horizontal and Vertical deflection motion

Ay, By Upper and Lower sensors for vertical deflection motion

X-OR Exclusive OR gate logic.

Manuscript received from Dr AZZAM, ATTIA EL-SBAIE on : $8 / 3 / 2000$

Accepted on : 25/3/2000

Engineering Research Bulletin, Vol 23,No 2, 2000 Minufiya University, Faculty of Engineering, Shebien El-Kom, Egypt, ISSN 1110-1180 


\section{INTRODUCTION:}

In remote area, a single diesel generator often supplies electricity. But, this is unreliable and costly. Also, the unavailability of commercial fuels in remote areas offers a rewording operation and utilization of locally available renewable energy sources. These sources can be used to supply residential electrical loads and water pumping in rural and remote areas. The main type of these sources pertaining the meteorological conditions of many of the world countries as well as in Egypt is solar photovoltaic systems. This is due to the solar energy is nondeplatable, inexhaustible and clean resource. It is generally acceptable that photovoltaic system will be one of the costcompetitive contenders for electric power generation in the future.

With increased use of PV systems, more attention is bought to their design and optimum utilization in order to achieve the most reliable and economical operation. It is of great interest to develop a control system that will track the sun for maximizing the output power of PV array. This control system using an electronic control devices known as maximum power point tracker [1]. In previous publications for tracking PV system, the value of PV-array-tiltangle is varied hourly as a function of the hourly sun-tilt-angle [2], but in this paper the PV array would be perpendicular facing the sun along the day by using two tracking subsystems, one for horizontal equilibrium and the other for vertical ones.

\section{SYSTEM ARCHITECTURE:}

In the design of the system architecture, the premise of allowing observing the behaviour of different parts of PV array, sensor, comparator, motor, and motor driver is taken into account. Therefore, the different elements are separately built using standard components that could easily emulate the behaviour of real devices in a plant as shown in fig. (1). The specifications of these devices are summarized as follows: 


\section{(1) PV array:}

PV system uses solar cells to convert the sun's energy into direct current electricity, which after being converted to alternating current can be used to supply electrical loads.

\section{(2) Sensor (transducer):}

Opt-electronics are frequently used by digital system to sense external conditions. The light or photons fall on the transducer's photosensitive base region and generate photocurrent $\left(\mathrm{I}_{b}\right)$. The resulting emitter current $\left(\mathrm{I}_{\mathrm{e}}\right)$ is equal to the transistor's current gain $\left(\mathrm{H}_{\mathrm{fe}}\right)$ multiplied by $\left(\mathrm{I}_{\mathrm{b}}\right)$. In the photo-darlington transistor detector, there is a two stages of transistor. These are detector's output current (the second-stage emitter current) which is equal to product of $\left(\mathrm{I}_{\mathrm{b}}\right)$ and the current gain of the two transistors. This detector therefore will produce a larger output current than that of the single-stage detector.

\section{(3) Comparator (differential-amplifier):}

In many applications, the signal to be amplified originates from a differential type source, such a transducer is used. The operational amplifier (op.amp.) is probably the most popular and versatile building block used in electronic circuitry. The output voltage is the difference of the input voltages applied to the two input terminals multiplied by the amplifier gain.

\section{(4)Stepper motor:}

A stepping motor is particularly well suited for this purpose, because it can be controlled by power amplifiers that need only respond to logic (two-state) signals, which will be generated from sensors. A stepping motor has coils that can be excited in proper sequence by on-off signals causing it to move through a predictable sequence of positions, taking one step each time the excitation changes states. As long as it isn't overloaded, it will hold a fixed position until an excitation change causes it to take another step. The size of the step is determined by the motor's geometry. Whenever the motor receives a pulse on the pulse-input 
hold a fixed position until an excitation change causes it to take another step. The size of the step is determined by the motor's geometry. Whenever the motor receives a pulse on the pulse-input line, it will take one step in the direction determined by the signal present on the direction control line.[3].

\section{System operation:}

Two identical lines tracking system are designed, one for horizontal equilibrium (Lx) and other for vertical one (Ly). The architecture of each line is shown in figure (1). This figure consists of two sensors, comparator, buffer, motor's driver, stepper motor, and mechanical coupling to PV array. To get a simple idea for the operation of a line tracking say ( $\mathrm{Lx}$ ), which has two sensors, one of them at the right edge (Ax) and the other at the left edge $(\mathrm{Bx})$, they have been put in a way that they have similar output, as the PV array is perpendicular to sun. Otherwise they will be in different output. Each sensor will be in bridge from which get high output in the case of sunny and low output in the case of shadow. The two outputs of sensors have to be fed to X-OR gate to decide the operation of motor or not, and other circuit has been designed to get the direction in case of motion.

Figure (2) shows a tracing diagram for the operation. There are three cases for the PV array position. The first is both $\mathrm{Ax}$ and $\mathrm{Bx}$ have the case of sunny or they have the case of shadow. This is the case of equilibrium ( no motion for motor). The second is Ax in the case of sunny, but Bx in the case of shadow, and this causes motor to move in a way to get the case of equilibrium. The third case is Ax in the case of shadow, and Bx in the case of sunny, and this causes motor moves in direction opposite to the previous second case.

\section{Conclusions:}

A simple low cost automatic control system for a PV array of solar cells has been designed. This control system is performed by a simple electronic circuits for horizontal and vertical motion to follow the sun. By means of this system the maximum power can be observed along the time. 


\section{References:}

[1], Hassan El-Sayed, Faten.f., Hussine.M, and Mostafa El-Shibini, "Matching of dc Pumping System with PV System Through Modified Maximum Power Points Tracker", the $6^{\text {th }}$ International Conference on Energy and Environment, Cairo, Egypt, 1998, pp.217-236.

[2], El-Zeftawy A.A.,"Optimal and Economical Sizing of Residential Photovoltaic Systems", Third Cairo International Conference on Renewable Energy Sources, Cairo, Egypt, Vol. 1, 1993, pp. 35-46.

[3], David, M. and Paul, S., "Microprocessor for Measurement and Control" Mc Graw-Hill, 1981 , P. 17.

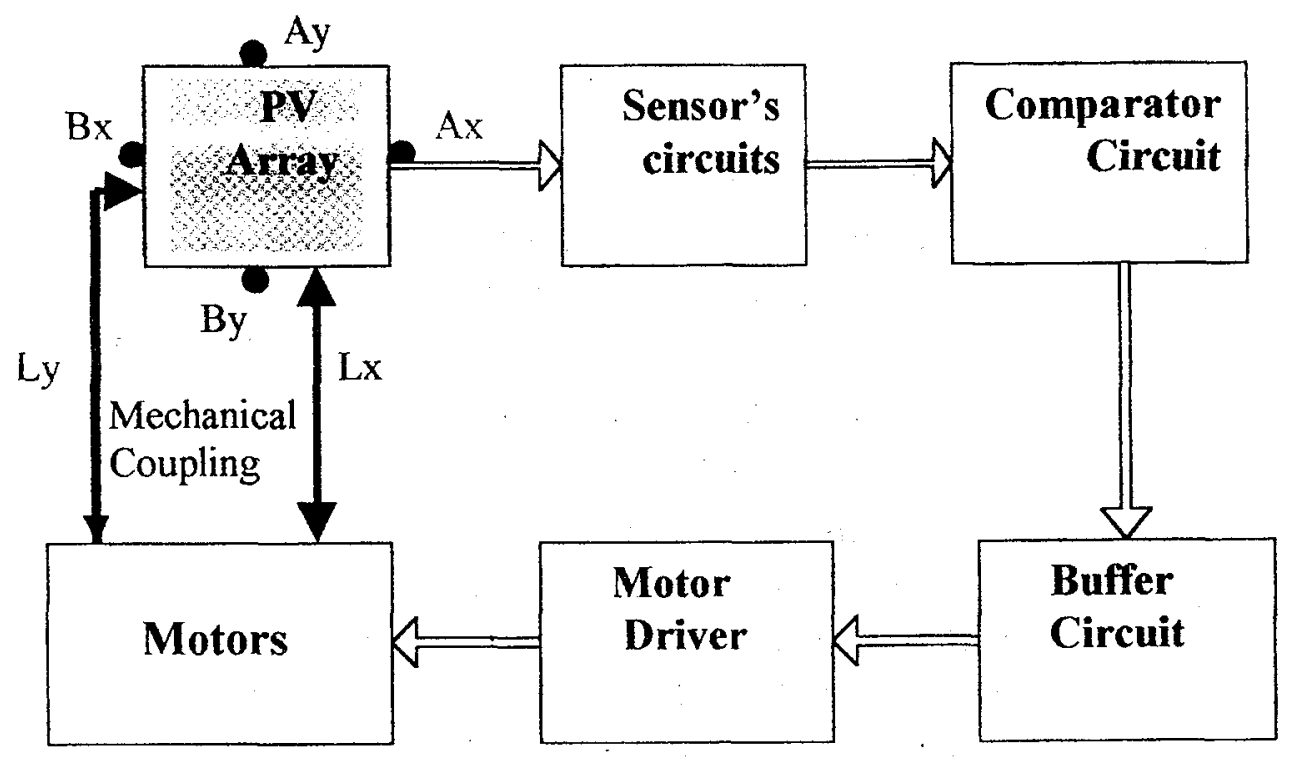

Fig. 1: Block diagram for closed loop control system of tracking PV system. 


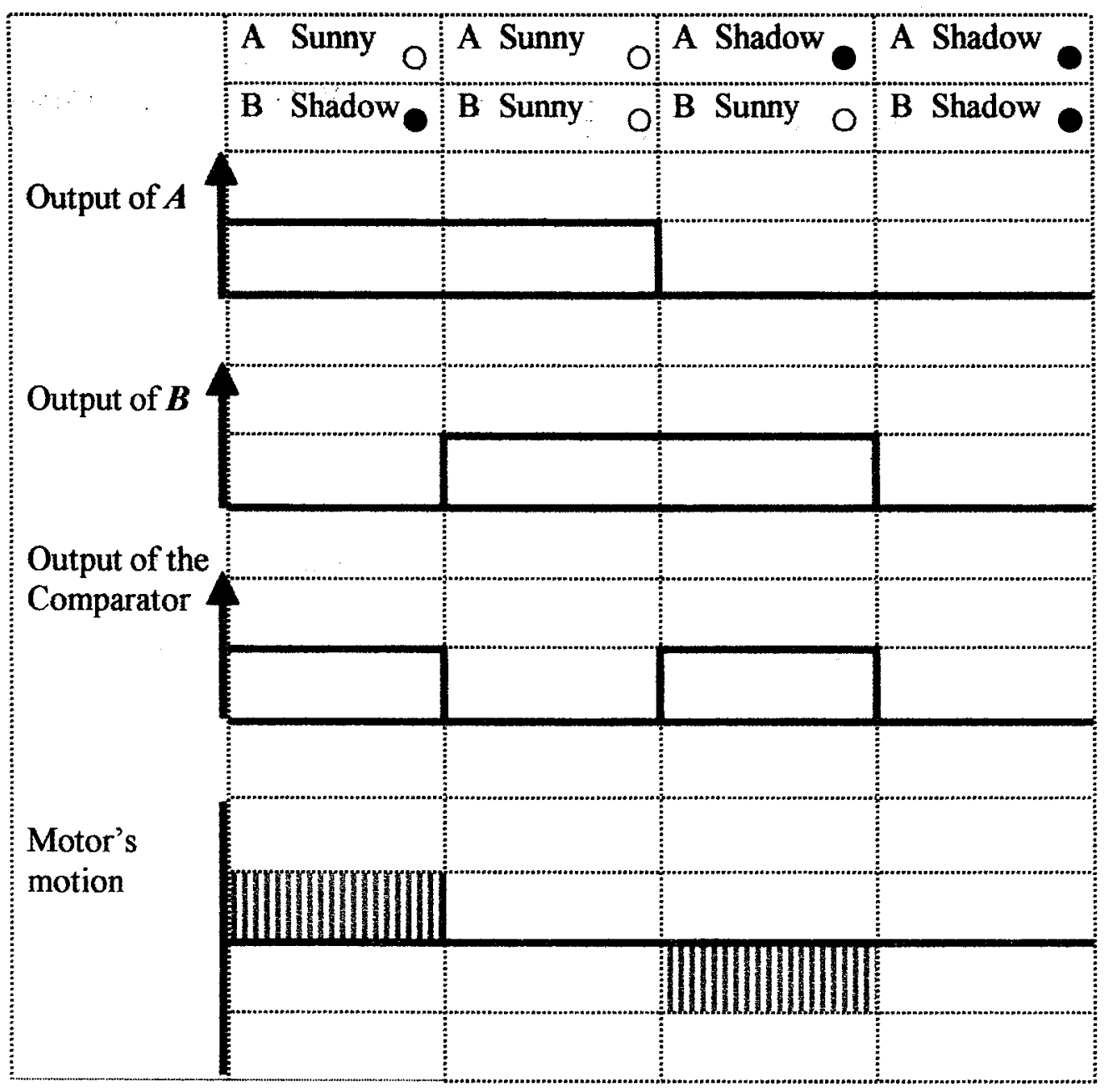

Fig. 2: Cases of Sun-Follower Deflection Diagram. 


\title{
نظام تحكم آلي في توجيه منظومة طاقة شمسية
}

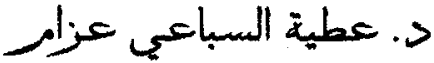

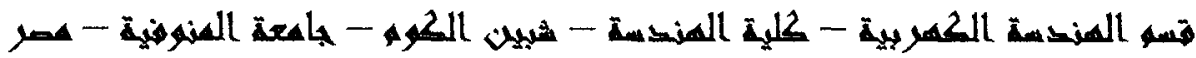

ملادة ما يستخدم البحث:

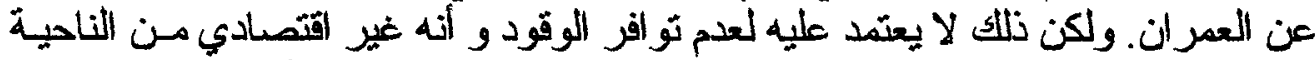

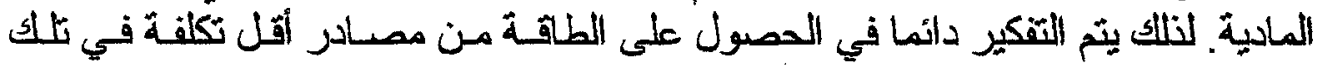

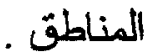

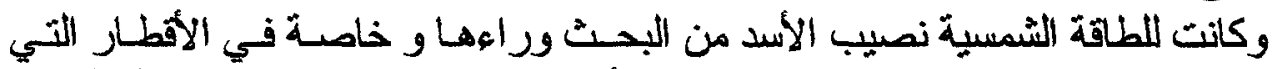

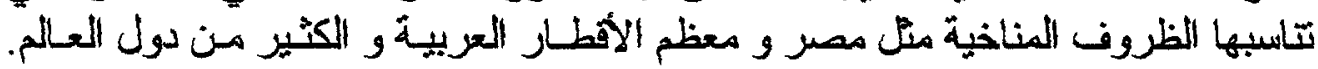
وكان ذلإن بالاتجاه نحو الستخدام الخلايا الشمسية.

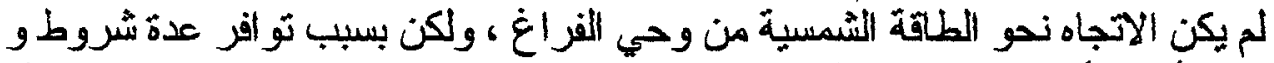

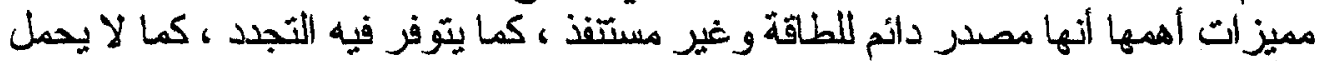

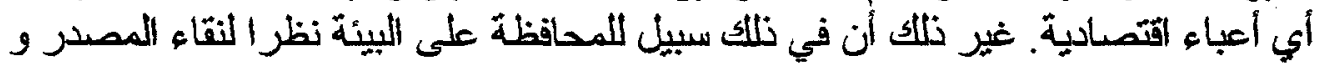

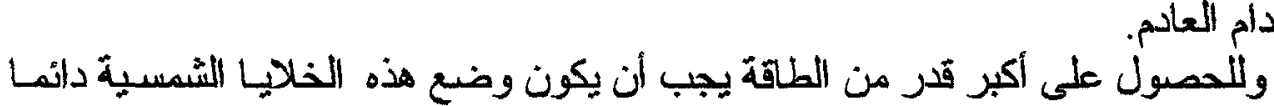

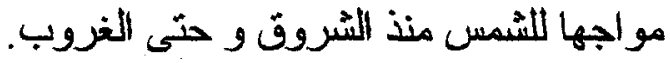

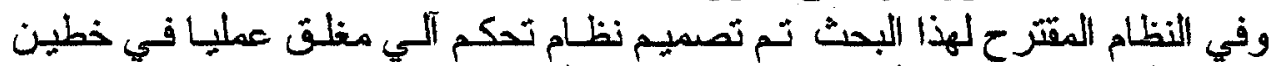

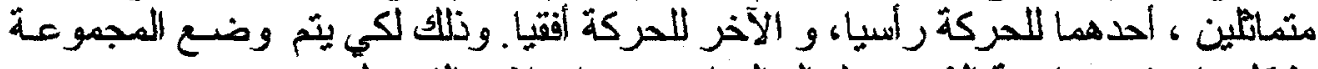

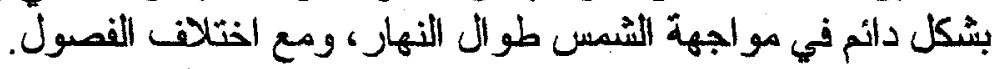

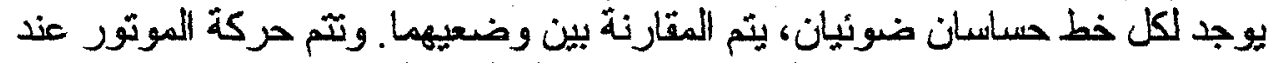

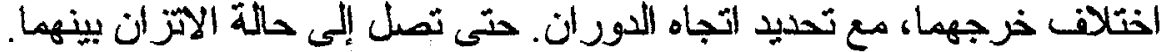

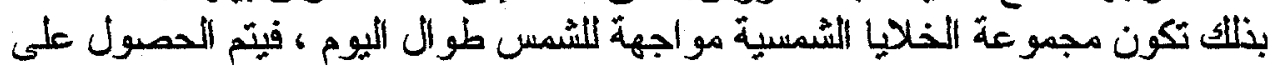

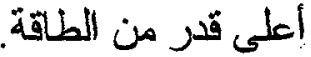

